\title{
Screening and Validation of a Novel Universal Target DNA Sequence for Simultaneous Identification and Differentiation of Bovine- and Ovine-/caprine- Derived Ingredients in Ruminant Feeds
}

\section{Zuhong Liu}

Huazhong Agricultural University: Huazhong Agriculture University

\section{Xiaokang Wang}

Huazhong Agricultural University: Huazhong Agriculture University

\section{Zengqiang Yan}

Huazhong Agricultural University: Huazhong Agriculture University

\section{Binbin Chu}

Huazhong Agricultural University: Huazhong Agriculture University

\section{Wenjun Wang}

Huazhong Agricultural University: Huazhong Agriculture University

Bang Liu ( $\sim$ liubang@mail.hzau.edu.cn )

Huazhong Agricultural University: Huazhong Agriculture University https://orcid.org/0000-0002-35396020

\section{Research}

Keywords: bovine, ovine/caprine, PCR, ruminant feeds, universal target sequence

Posted Date: January 26th, 2021

DOl: https://doi.org/10.21203/rs.3.rs-152598/v1

License: (c) (i) This work is licensed under a Creative Commons Attribution 4.0 International License.

Read Full License 


\section{Abstract}

Background: Ruminant feeds containing bovine- and ovine-/caprine- derived ingredients would increase the risk of transmissible spongiform encephalopathies (TSE) spread.

Results: In this study, a novel universal target DNA sequence was screened through genomic sequence alignment of 53 species, and an efficient and accurate PCR method was further developed to simultaneously identify and distinguish bovine- (125 bp) and ovine-/caprine- (107 bp) derived ingredients in ruminant feeds. The specificity of our PCR method was tested with 20 animal DNA and 3 feed material DNA. This novel universal target DNA sequence was specifically detected in only bovine species (including cattle, buffalo, yak, and zebu) and ovine/caprine species (including sheep and goat). Sensitivity analysis demonstrated that through this universal target sequence, as low as $1 \%$ heat-treated $\left(133^{\circ} \mathrm{C}, 300 \mathrm{kPa}\right.$ for $20 \mathrm{~min}$ ) meat and bone meal (MBM) of bovine or ovine species could be detected from in ruminant feeds.

Conclusions: In conclusion, this study screened a novel universal target DNA sequence, designed a universal primer pair, and developed an efficient and accurate PCR method for the simultaneous identification and differentiation of bovine- and ovine/caprine- derived ingredients in ruminant feeds.

\section{Background}

The wide spread of transmissible spongiform encephalopathy (TSE) has not only caused huge economic losses in livestock industry, but also severely threatened human health (Greenlee and Greenlee, 2015; Schaffert and Carter, 2020). This disease mainly spreads through ruminant feeds which were supplemented with infected animal ingredients (especially from bovine, ovine, and caprine species) (Kumagai, Daikai and Onodera, 2019; Lecrenier et al., 2020). To prevent, control, and eradicate TSE, the European Union (EU) has amended and passed the Decision 2019/319 to prohibit the import of bovine, ovine, and caprine products from the countries or regions with TSE risk. Therefore, it is of great significance to develop a technology for the detection of bovine-, ovine- and caprine- derived ingredients from ruminant feeds.

Optical microscopy, Fourier transform infrared spectroscopy, and enzyme-linked immunosorbent assay have been developed and applied for the detection of animal-derived ingredients from feeds (Rao and Hsieh, 2008; European Commission, 2013; Gao et al., 2017). DNA-based PCR methodologies are popular due to their high stability of DNA in highly-processed feeds (Safdar and Junejo, 2015a; Kppel et al., 2020). Many target DNA sequences have been screened for the detection of bovine, ovine and caprine in ruminant feeds. Several single PCR detection methods, specifically targeting 12S rRNA, ND1 gene, and $C y t-b$ gene, have been reported for detecting bovine-, ovine-, and caprine- derived ingredients, respectively (Martín et al., 2008; Karabasanavar et al., 2011; Kumar et al., 2015). To improve the detection efficiency, multiplex PCR methods have been developed to simultaneously detect bovine-, ovine-, and caprinederived ingredients in feeds using multiple target DNA sequences (Martín et al., 2007a; Safdar et al., 
2014). However, using multiple target sequences in one reaction will reduce detection sensitivity (Bai et al., 2009). To further simplify reaction system, several universal target sequences have been screened from mtDNA for the simultaneous detection of multiple animal-derived ingredients (Bottero et al., 2003; Xue et al., 2017; Zhang et al., 2017). Although the existing methods allow the simultaneous amplification of target sequences of bovine, ovine, and caprine with one pair of universal primers, additional restriction enzymes or sequencing are inevitably required to distinguish amplification fragments, resulting in the increased detection cost and time. These existing methods for detecting multiple animal-derived ingredients in ruminant feeds are of low detection efficiency and poor accuracy due to the lack of suitable target sequences. Therefore, it is still necessary to identify a novel universal target sequence and to establish an efficient and accurate PCR method for the detection of bovine-, ovine- and caprine- derived ingredients in ruminant feeds.

The objective of the present study was to screen a novel DNA sequence as a universal target sequence of bovine, ovine and caprine, and to design a universal primer pair in the conserved region of this universal target sequence for specific identification of bovine- and ovine-/caprine- derived ingredients. A novel efficient and accurate PCR method would be further developed and applied for simultaneous identification and differentiation of bovine- and ovine-/caprine- derived ingredients in ruminant feeds.

\section{Methods}

\section{Sample collection}

Muscle and organ tissue (including heart, liver, lung, spleen, and intestine) samples from cattle, sheep, and goat were provided by a local slaughter house. Raw meat samples from buffalo, yak, horse, donkey, pig, chicken, duck, goose, and rabbit were purchased from local markets. DNA samples of rat, mouse, hamster, guinea pig, and dog were obtained from Veterinary Hospital (Huazhong Agricultural University, Wuhan, China). DNA samples of deer, fox, mink, raccoon dog, zebu, small tailed Han sheep, Merinos sheep, Hu sheep, Mongolian sheep, and Mongolian goat were obtained from Laboratory Animal Center (Huazhong Agricultural University, Wuhan, China). Feed ingredients including fish meal, maize, and soybean meal were provided by Hubei Feed Quality Station of Analysis and Supervisor (Huazhong Agricultural University, Wuhan, China). All animal samples were transported to the laboratory under refrigeration, and processed immediately or frozen stored at $-80{ }^{\circ} \mathrm{C}$ until used.

\section{Preparation of binary meat mixture samples, artificial feed samples, and commercial feed samples}

To evaluate the co-detection ability of our method, different percentages of binary meat mixture samples were made in laboratory. Cattle and sheep muscle samples were dried in oven $\left(65^{\circ} \mathrm{C}\right.$ for $\left.120 \mathrm{~min}\right)$, smashed in grinder, and mixed at a weight/weight (w/w) ratio of 100:0, 95:5, 90:10, 75:25, 50:50, 25:75, $10: 90,5: 95$, and 0:100, respectively. All binary meat mixture samples were made to reach a final weight of $100 \mathrm{~g}$ using a blender (Sunbeam Oster, Florida, USA) and stored at $-20^{\circ} \mathrm{C}$ until use. 
To evaluate the sensitivity of our method, artificial feed samples were prepared by mixing different percentages of bovine or ovine/caprine meat and bone meal (MBM) with soybean meal. According to the practical production procedure of MBM (European Commission, 2009), bovine MBM was made by mixing equal amount of cattle organ tissues (liver, lung, spleen, and intestine) and treating them at $133{ }^{\circ} \mathrm{C}, 300$ $\mathrm{kPa}$ for $20 \mathrm{~min}$ in autoclave (GR60DA; Zealway Instrument Inc., Delaware, USA). Ovine/caprine MBM was a mixture of heart, liver, lung, and intestine tissues from sheep, whose processing method was same with that of bovine MBM. Subsequently, binary mixtures mixing $0.1 \%, 1 \%, 5 \%, 10 \%, 25 \%$, and $50 \%(\mathrm{w} / \mathrm{w})$ heattreatment MBM (bovine or ovine/caprine) and soybean meal were prepared into artificial feed samples.

To further evaluate the applicability of our method in commercial feeds, a feed mill (Shandong Tianpu Sunshine Feed Co., Ltd., Shandong, China) was commissioned for preparing five commercial feed samples. The actual production process of commercial feed samples included crushing, puffing, steam quenching, and granulation ( $90^{\circ} \mathrm{C}, 800 \mathrm{kPa}$ for $20 \mathrm{~min}$ ). According to our request, $1 \%$ of bovine MBM, ovine/caprine MBM, or fish meal was randomly incorporated to five commercial feed samples, and the detail adulteration information was unavailable to us.

\section{DNA extraction}

The extraction of sample genomic DNA was carried out according to the proteinase K-sodium dodecyl sulfate (SDS)-phenol/chloroform protocol (Reid, 1991), with minor modifications. The detailed descriptions were presented in E-Supplementary. The concentration and purity of all the genomic DNA extracts were measured using Nanodrop 2000 (Thermo Scientific, USA). In addition, the integrity of DNA extracted from raw and heated tissues was checked by $1 \%$ agarose gel electrophoresis in $0.5 \times$ TBE

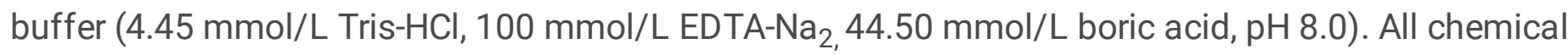
reagents were purchased from Shanghai Hushi Testing Equipment Co., Ltd (Shanghai, China).

\section{Screening of universal target DNA sequence}

DNA sequences of cattle were aligned with homologous sequences of other species (without bovine, ovine and caprine) available in GenBank by using the Basic Local Alignment Search Tool (BLAST). The sequences with the alignment parameters of Identity $<90 \%$ and Query-length $>200$ bp were further aligned with the whole genome sequences of other bovines (zebu, yak, bison, and buffalo), ovine (sheep), and caprine (goat), respectively. The sequences with Identity $>95 \%$ were selected as specific sequences for bovine, ovine, and caprine species (Figure 1). For the convenience and efficiency of detection, a DNA fragment with 18 bp sequence deletion in both ovine and caprine genomes was selected as speciesspecific sequence. Genome sequence alignments of 53 species including representative species of 4 kingdoms, 10 classes, 21 orders, 36 families and 47 genera (cattle, zebu, yak, bison, buffalo, horse, przewalskii horse, donkey, sheep, goat, deer, camel, pig, rabbit, fox, dog, wolf, dingo, cat, bear, ferret, monkey, human, mouse, rat, jerboa, hamster, guinea pig, squirrel, beaver, pika, dolphin, whale, elephant, bat, hedgehog, chicken, turkey, duck, goose, ostrich, anole, frog, zebrafish, salmon, fruit fly, soybean, maize, rice, wheat, yeast, Escherichia coli, and Salmonella) were performed by BLAST and ClustaIW. 


\section{Primer design}

Species-specific primer pair were designed in the conserved region using Primer Premier 5.0 (Premier, San Francisco, CA, USA) for specific detection of target sequences of bovine, ovine, and caprine species. The size of amplified fragment was set to be shorter than $200 \mathrm{bp}$ with at least $10 \%$ difference between bovine and ovine/caprine DNA. The sequences of novel universal primer pair were shown in Table. 1. Moreover, a previously reported internal reference primer pair were used for the amplification of a conserved fragment of $18 S$ rRNA from animal and plant species in this study (Yun et al., 2018). All the primer pairs were diluted to $10 \mu \mathrm{mol} / \mathrm{L}$ for preservation.

\section{PCR amplification}

To optimize PCR system, the concentrations of universal primer pair were set as $0.1 \mu \mathrm{mol} / \mathrm{L}, 0.2 \mu \mathrm{mol} / \mathrm{L}$, $0.3 \mu \mathrm{mol} / \mathrm{L}$, and $0.4 \mu \mathrm{mol} / \mathrm{L}$ to amplify the target fragment of cattle and sheep, and annealing temperatures were set as $58{ }^{\circ} \mathrm{C}, 60^{\circ} \mathrm{C}, 62^{\circ} \mathrm{C}$, and $64{ }^{\circ} \mathrm{C}$, respectively. As shown in E-Supplementary Figure S1, the amount of amplified products reached the maximum for both cattle and sheep without dimers produced, when the concentration of universal primer pair was $0.2 \mu \mathrm{mol} / \mathrm{L}$ and the annealing temperature was $62{ }^{\circ} \mathrm{C}$. Thus, the PCR amplification was carried out at a total volume of $20 \mu \mathrm{L}$ containing $50 \mathrm{ng}$ of template DNA, $0.2 \mu \mathrm{mol} / \mathrm{L}$ of each primer, $1 \times \mathrm{PCR}$ buffer, $2 \mathrm{mmol} / \mathrm{L} \mathrm{MgCl}_{2}, 0.2$ $\mathrm{mmol} / \mathrm{L}$ of deoxynucleoside triphosphates (dNTPs), $0.5 \mathrm{U}$ rTaq polymerase (TaKaRa Bio Inc., Otsu, Japan), and sterile distilled water. PCR conditions of universal primer pair were as follows: an initial heat denaturation at $95^{\circ} \mathrm{C}$ for 5 min, followed by 35 cycles of DNA denaturation at $95^{\circ} \mathrm{C}$ for $30 \mathrm{~s}$, primer pair annealing at $62{ }^{\circ} \mathrm{C}$ for $30 \mathrm{~s}$, and DNA extension $72{ }^{\circ} \mathrm{C}$ for $15 \mathrm{~s}$. The last step was the extension at $72{ }^{\circ} \mathrm{C}$ for $3 \mathrm{~min}$. In addition, the PCR reaction system and PCR procedures of internal reference primer pair referred to previous report by Yun et al. (2018). The PCR was performed in a thermal cycler (Bio-Rad Laboratories, Inc., USA). The amplified products were analyzed by $2.5 \%$ gel electrophoresis in $0.5 \times$ TBE and were sequenced by TSINGKE Biotech co., Ltd (Beijing, China).

\section{Results And Discussion}

\section{Universal target DNA sequence screening for detecting bovine and ovine/caprine ingredients}

A conservative nuclear DNA sequence ( $200 \mathrm{bp}$ ) from cattle TATA-box-binding protein-associated factor 4 gene (TAF4) (GenBank: NC_037340.1) was screened as universal target sequence for specifically detecting bovine (cattle, zebu, yak, bison, and buffalo), ovine (sheep), and caprine (goat) DNA. The universal target sequence was aligned against the genomic DNA sequences of 53 representative species through BLAST. As shown in Figure 1, the species-specific target DNA sequence exhibited good specificity, compared with the reference genomes of other species. The DNA sequences of only eight species (cattle, zebu, yak, bison, buffalo, sheep, goat, and deer) were identified as homologous sequences. These homologous sequences were downloaded and aligned using ClustalW. The results demonstrated the differences and the high conservation among the sequences of these eight species. Within these 8 
species DNA sequences, the regions (125 bp) different from the genome sequences of other species were selected for designing novel universal primer pair. It has been reported that critical mismatches in the universal primer binding regions would lead to the failure of PCR amplification (Kirsten et al., 2007). Figure 1 showed the mismatch of deer sequence at the 3 'end of primer binding regions, resulting in the failure of deer sequence to bind the universal primer pair. Meanwhile, the conservation of the novel universal primer binding regions within bovine, ovine and caprine species was a crucial factor affecting the accuracy of detection. The $18 \mathrm{bp}$ region deletion in ovine and caprine genome sequences allowed to distinguish bovine amplified fragments (125 bp) from ovine/caprine ones (107 bp), which could greatly improve detection efficiency.

It has been reported that the size of screened target DNA sequence should be set to be shorter than 200 bp due to the serious damage of DNA by heat-treatment of ruminant feeds $\left(133^{\circ} \mathrm{C}, 300 \mathrm{kPa}\right.$ for $\left.20 \mathrm{~min}\right)$ (Martín et al., 2007b). However, the sizes of universal target DNA sequence for bovine, ovine and caprine species in previous studies were usually more than 200 bp (Xue et al., 2017; Guan et al., 2018), which might lead to poor sensitivity and false negative results in feed detection. In contrast, the universal target DNA sequence sizes for bovine (125 bp) and ovine/caprine (107 bp) species in our study were more appropriate for detecting heat-treated feeds, which could greatly ensure detection accuracy.

\section{Specificity and conservation test}

The specificity of the PCR method was tested with DNA from 20 animal species (including 17 mammals and 3 birds) and 3 feed materials (including fish meal, maize, and soybean meal). The result showed that species-specific amplified fragments were detected only in cattle, buffalo, sheep, and goat species with completely different amplification fragment sizes for bovine (125 bp) and ovine/caprine (107 bp) species. No amplification products were found in other species (Figure $2 \mathrm{~A}$ ). As shown in the $\mathrm{E}$ Supplementary Figure S2, the amplifications of the corresponding size were detected in different bovine species (including buffalo, zebu, and yak) and ovine/caprine breeds (including small tailed Han sheep, Merinos sheep, Hu sheep, Mongolian sheep, and Mongolian goat).

Because a large variety of animal and plant materials could be added into ruminant feeds, specificity test against a large number of species was very important (Martín et al., 2007b; Nikkhah, 2012). In our study, species specificity was determined by sequence alignment among 53 species using BLAST and further confirmed in 20 animal species and 3 feeds materials by PCR. Some previous studies have reported that buffalo, zebu, and yak in Bovidae are the potential carriers and spreaders of TES (Seuberlich et al., 2006; Wang et al., 2014; Zhao et al., 2015). As shown in the E-Supplementary Figure S2, the accuracy of our method was confirmed in bovine and ovine/caprine samples from different species/breeds and individuals, which could efficiently avoid false negative results. In addition, DNA degradation, equipment deficiency, and presence of nucleic acid inhibitors might lead to the failures of amplification reactions (Safdar and Junejo, 2015a). Therefore, an internal reference primer pair that could amplify a conserved region of gene (181 bp) in all the species possibly occurring in the feeds was used for specificity test to further avoid the occurrence of false negative results (Figure 2B) (Yun et al., 2018). 


\section{Sensitivity}

To test the sensitivity of the PCR method, cattle or sheep genomic DNA at different concentrations (20 ng, $10 \mathrm{ng}, 2 \mathrm{ng}, 1 \mathrm{ng}, 0.2 \mathrm{ng}, 0.1 \mathrm{ng}, 0.02 \mathrm{ng}$, and $0 \mathrm{ng}$ ) were tested in developed PCR system. The results showed that the sensitivity of both cattle and sheep was $0.1 \mathrm{ng}$ in our PCR system (Figure 3A). Moreover, sensitivity test results of the artificial feed samples showed that no less than $1 \%$ addition of cattle or sheep MBM into feed could be detected (Figure 3B). Because less than $1 \%$ supplementation of bovine, ovine, or caprine MBM as animal protein source in feeds was far from enough, the sensitivity of our method was relatively suitable for the detection of feed samples.

\section{Co-detection test of bovine and ovine/caprine species}

In our study, the co-detection ability of the PCR method for bovine and ovine/caprine species was investigated with DNA from binary meat mixture samples of cattle and sheep muscles at the different ratios of $100: 0,95: 5,90: 10,75: 25,50: 50,25: 75,10: 90,5: 95$ and $0: 100(\mathrm{w} / \mathrm{w})$. The results showed the ingredients of cattle and sheep could be clearly detected in different ratios of mixed muscle samples (as shown in Figure 4). When both cattle and sheep muscle sample DNA were present in one PCR system, the third amplified fragment different from cattle's and sheep's fragments appeared on agarose gel. This third amplified fragment might be the hybrid fragment combined by the amplified fragments of cattle and sheep due to the high base repetition rate, and this hybrid fragment could work as a specific marker for the simultaneous detection of bovine and ovine/caprine ingredients.

Bovine, ovine, and caprine MBM might be added into ruminant feeds as collectively rather than individually (Safdar and Junejo, 2015b), so it is of great significance to develop an efficient detection method for the co-identification of bovine, ovine and caprine ingredients. In previous studies, several multiplex PCR methods have been developed for the simultaneous detection of bovine, ovine and caprine ingredients (Martín et al., 2007a; Safdar et al., 2014; Lee et al., 2016). Although multiplex PCR could increase detection efficiency, the use of multiple primer pairs or fluorescent probes would lead to reaction system complexity, low amplification efficiency, and increased detection cost (Bai et al., 2009). In contrast, the novel universal target DNA sequence screened in our study was in the genomic conserved region of bovine and ovine/caprine species, and a there existed $18 \mathrm{bp}$ deletion in ovine and caprine species, which allowed the specific simultaneous detection and distinction of bovine and ovine/caprine ingredients by gel electrophoresis. To the best of our knowledge, the novel universal primer pair which could achieve the efficient and accurate co-detection and distinction of bovine and ovine ingredients in heat-treated feeds by gel electrophoresis, was firstly proposed in our study.

\section{Application of the PCR method to commercial feed samples}

To assess the applicability of our PCR method, five commercial feed samples were analyzed by the developed PCR method. The DNA of five commercial feed samples were extracted for PCR detection under the optimal amplification system and conditions (Figure 5). Our results indicated that both bovine and ovine/caprine ingredients were detected in the NO.1 sample, the bovine ingredient was detected in the 
NO.2 sample, and ovine/caprine ingredients were detected in the NO.3 and NO.4 samples. The speciesspecific fragment was not amplified in the No.5 sample. No amplified fragments were observed in the negative control or the blank control. These animal ingredient detection results were found to be in accordance with the actual supplementation of bovine and ovine/caprine ingredients into five commercial feed samples by feed mill.

In the production processing of commercial feeds, animal DNA were severely destroyed twice. Firstly, MBM was treated at $133^{\circ} \mathrm{C}, 300 \mathrm{kPa}$ for $20 \mathrm{~min}$ according to the general hygiene requirements (European Commission, 2009), then MBM was mixed with other feed ingredients, and finally, commercial feeds were obtained by crushing, puffing, steam quenching, and granulation ( $90^{\circ} \mathrm{C}, 800 \mathrm{kPa}$ for $20 \mathrm{~min}$ ). It was hard to accurately simulate the second DNA damage under laboratory conditions. Therefore, it is crucial to validate the applicability of our PCR method for detecting bovine- and ovine-/caprine-derived ingredients in commercial feed samples. The detection results of five commercial feed samples by using our method were completely consistent with the actual supplementation. Both singly and collectively supplemented bovine and ovine/caprine ingredients were clearly detected and the different types of ingredients were distinguished in commercial samples. Thus, the efficient and accurate PCR method we developed is competent for the actual detection of feed samples.

\section{Conclusions}

An efficient and accurate PCR method based on a novel universal DNA target sequence has been developed and further applied to the detection and distinction of bovine- and ovine-/caprine- derived ingredients in ruminant feeds. The specific universal DNA target sequence in the TAF4 gene region was creatively screened, and a novel universal primer pair were designed in terms of intraspecies homogeneity and interspecies heterogeneity across 53 species. The sizes of amplified fragments were different for bovine (125 bp) and ovine/caprine (107 bp) species, which could further distinguish bovine from ovine/caprine species by gel electrophoresis. Besides, our PCR method can indiscriminately detect different bovine species (cattle, buffalo, yak, and zebu) and various ovine/caprine breeds (including small tailed Han sheep, Merinos sheep, Hu sheep, Mongolian sheep, and Mongolian goat), which can avoid false negative results. Moreover, the detection of mixed feed samples and commercial feed samples further confirmed the applicability of our PCR method. Thus, our PCR method can conveniently detect bovine- and ovine/caprine-derived ingredients forbidden in ruminant feeds with $0.1 \mathrm{ng}$ or $1 \%$ sensitivity. These results show that our PCR method based on the novel universal primer pair has great potential and application prospect for feed supervision and market management.

\section{List Of Abbreviations}

BLAST, basic local alignment search tool

EU, European Union 
MBM, meat and bone meal

TAF4, TATA-box-binding protein-associated factor 4 gene

TSE, transmissible spongiform encephalopathy

\section{Declarations}

\section{Ethics approval}

The experimental procedures were reviewed and approved by the Animal Care and Use Committee of College of Animal Science and Technology, Huazhong Agricultural University (Committee of Science and Technology).

\section{Consent for publication}

Not applicable.

\section{Availability of data and material}

All data and material generated or analyzed during this study are included in this published article.

\section{Competing interests}

The authors declare that they have no competing interests.

\section{Funding}

This work was supported by the Major Nature Science Foundation of China (31930104) and the China Postdoctoral Science Foundation (2020M682445).

\section{Authors' contributions}

ZL completed the entire experiments with the assistance of WW, XW and ZY. ZL and BC participated in sample collection. BL and WW got the funding and designed the experiments. ZL wrote the manuscript. All authors read and approved the final manuscript.

\section{Acknowledgements}

Great gratitude goes to linguistics professor Ping Liu from Foreign Language College, Huazhong Agriculture University, Wuhan, China for her work at English editing and language polishing.

\section{References}


1. Bai W, Xu W, Huang K, Yuan Y, Cao S, Luo Y. A novel common primer multiplex PCR (CP-M-PCR) method for the simultaneous detection of meat species. Food Control. 2009; doi:10.1016/j.foodcont.2008.05.021.

2. Bottero MT, Civera T, Nucera D, Turi RM. Design of universal primers for the detection of animal tissues in feedstuff. Vet. Res. Commun. 2003; doi:10.1023/B:VERC.0000014243.75976.cd.

3. European Commission (EC). Commission regulation No 1069/2009 of 21 October 2009 laying down health rules as regards animal by-products and derived products not intended for human consumption and repealing Regulation (EC) No 1774/2002 (Animal by-products Regulation). Off. J. Eur. Communities: Legis. 2009. https://eur-lex.europa.eu/legal-content/EN/TXT/? uri=CELEX\%3A32009R1069\&qid=1610075195226. Accessed 17 Dec 2020.

4. European Commission (EC). Commission regulation No 51/2013 of 16 January 2013 amending Regulation (EC) No 152/2009 as regards the methods of analysis for the determination of constituents of animal origin for the official control of feed. J. Eur. Communities: Legis. 2013. https://eurlex.europa.eu/legalcontent/EN/TXT/?uri=CELEX\%3A3213R00051\&qid=1610077510030. Accessed 17 Dec 2020.

5. European Decision. Commission regulation No 319/2019 of 6 February 2019 amending Annex IX to Regulation (EC) No 999/2001 of the European Parliament and of the Council and Annex XV to Commission Regulation (EU) No 142/2011 as regards health certification at import into the Union concerning transmissible spongiform encephalopathies. Off. J. Eur. Communities: Legis. 2019. https://eur-lex.europa.eu/legal-content/EN/TXT/?uri=CELEX\%3A32019R0319\&qid=1610078038401. Accessed 17 Dec 2020.

6. Gao F, Xu L, Zhang Y, Yang Z, Han L, Liu X. Analytical raman spectroscopic study for discriminant analysis of different animal-derived feedstuff: understanding the high correlation between raman spectroscopy and lipid characteristics. Food Chem. 2018; doi:10.1016/j.foodchem.2017.07.143.

7. Greenlee JJ, Greenlee MHW. The transmissible spongiform encephalopathies of livestock. ILAR J. 2015; doi:10.1093/ilar/ilv008.

8. Guan F, Jin YT, Zhao J, Xu AC. A PCR method that can be further developed into PCR-RFLP assay for eight animal species identification. J. Anal. Methods Chem. 2018; doi:10.1155/2018/5890140.

9. Karabasanavar NS, Singh SP, Umapathi V, Kumar D, Patil G, Shebannavar SN. A highly specific PCR assay for identification of raw and heat treated mutton (Ovis aries). Small Ruminant Research. 2011; doi:10.1016/j.smallrumres.2011.07.009.

10. Kirsten H, Teupser D, Weissfuss J, Wolfram G, Emmrich F, Ahnert P. Robustness of single-base extension against mismatches at the site of primer attachment in a clinical assay. J. Mol. Med. 2007; doi:10.1007/s00109-006-0129-2.

11. Kppel R, Ganeshan A, Ledermann R, Velsen FV. Detection of animal DNA in vegan food by multiplex qPCR-system. Eur. Food Res. Technol. 2020; doi:10.1007/s00217-020-03608-7.

12. Kumagai S, Daikai T, Onodera T. Bovine Spongiform Encephalopathy - A Review from the Perspective of Food Safety. Food Saf. 2019; doi:10.14252/foodsafetyfscj.2018009. 
13. Kumar AA, Kumar RRA, Sharma BDA, Mendiratta SKA, Gokulakrishnan PA, Sharma DAB. Authentication of goat (Capra hircus) meat using PCR amplification of mitochondrial cytochrome $b$ gene. Small Ruminant Research. 2015; doi:10.1016/j.smallrumres.2015.07.016.

14. Lecrenier MC, Veys P, Fumiere O, Berben G, Baeten V. Official feed control linked to the detection of animal by-products: past, present and future. J. Agric. Food Chem. 2020; doi:10.1021/acs.jafc.0c02718.

15. Lee JH, Kim MR, Jo CH, Jung YK, Kwon K, Kang TS. Specific PCR assays to determine bovine, porcine, fish and plant origin of gelatin capsules of dietary supplements. Food Chem. 2016; doi:10.1016/j.foodchem.2016.05.060.

16. Martín I, García T, Fajardo V, López-Calleja I, Rojas M, Pavón MA, et al. Detection of chicken, turkey, duck and goose tissues in feedstuffs using species-specific polymerase chain reaction. J. Anim. Sci. 2007a; doi:10.2527/jas.2006-350.

17. Martín I, García T, Fajardo V, López-Calleja I, Hernández PE, González I, et al. Species-specific PCR for the identification of ruminant species in feedstuffs. Meat Sci. 2007b; doi:10.1016/j.meatsci.2006.06.019.

18. Martín I, García T, Fajardo V, Rojas M, Hernández PE, González I, et al. Real-time PCR for quantitative detection of bovine tissues in food and feed. J. Food Prot. 2008; doi:10.4315/0362-028x-71.3.564.

19. Nikkhah A. Barley grain for ruminants: A global treasure or tragedy. J. Anim. Sci. Biotechnol. 2012; doi:10.1186/2049-1891-3-22.

20. Rao Q, Hsieh YH. Competitive enzyme-linked immunosorbent assay for quantitative detection of bovine blood in heat-processed meat and feed. J. Food Prot. 2008; doi:10.4315/0362-028x71.5.1000.

21. Reid GA. Molecular cloning: A laboratory manual. (2nd ed.). Cold Spring Harbor Laboratory Press; 1991.

22. Safdar M, Junejo Y. Development and validation of fast duplex real-time PCR assays based on SYBER Green florescence for detection of bovine and poultry origins in feedstuffs. Food Chem. 2015a; doi:10.1016/j.foodchem.2014.10.088.

23. Safdar M, Junejo Y. A multiplex-conventional PCR assay for bovine, ovine, caprine and fish species identification in feedstuffs: Highly sensitive and specific. Food Control. 2015b; doi:10.1016/j.foodcont.2014.08.048.

24. Safdar M, Junejo Y, Arman K, Abasıyanık MF. Rapid bovine and caprine species identification in ruminant feeds by duplex real-time PCR melting curve analysis using EvaGreen fluorescence dye. Mol. Biotechnol. 2014; doi:10.1007/s12033-014-9756-y.

25. Schaffert LN, Carter WG. Do Post-Translational Modifications Influence Protein Aggregation in Neurodegenerative Diseases: A Systematic Review. Brain Sci. 2020; doi:10.3390/brainsci10040232.

26. Seuberlich T, Botteron C, Wenker C, Café-Marçal V, Oevermann A, Haase B, et al. Spongiform encephalopathy in a miniature zebu. Emerging Infect. Dis. 2006; doi:10.3201/eid1212.060750. 
27. The Basic Local Alignment Search Tool. National Center for Biotechnology Information (NCBI), USA. 2020. https://blast.ncbi.nlm.nih.gov/Blast.cgi. Accessed 20 May 2020.

28. The ClustalW. Kyoto University Bioinformatics Center, Japan. 2020. https://www.genome.jp/toolsbin/clustalw. Accessed 12 May 2020.

29. The GenBank. National Center for Biotechnology Information (NCBI), USA. 2020. https://www.ncbi.nlm.nih.gov/genbank/. Accessed 11 May 2020.

30. Wang LH, Xi DM, Li GZ, Hu JH. The relationship of two loci polymorphisms of the prion protein gene on resistance to bovine spongiform encephalopathies in yak. Acta Ecologae Animalis Domastici. 2014; doi:1005-5228(2014)02-0015-06.

31. Xue C, Wang P, Zhao J, Xu A, Guan F. Development and validation of a universal primer pair for the simultaneous detection of eight animal species. Food Chem. 2017;

doi:10.1016/j.foodchem.2016.11.102.

32. Yun ZY, Li WJ, Huo SN, Wu Q, Wang J, Zhao L, et al. Rapid detection for animal-derived materialsMembrane-based array method. China National Institute of Standardization. 2018. http://www.gb688.cn/bzgk/gb/newGblnfo?hcno=EF7DFF38A7A7DA1DF6 AE2F854B1869FB. Accessed 17 Dec 2020.

33. Zhang Y, Yang XY, He JP, Cui WT, Zhang ZX, Chang JJ, et al. A detection method and primer pairs designed for the species identification in mixed animal materials. National Intellectual Property Administration of China. 2017. http://cprs.patentstar.com.cn/Search/Detail? ANE=6AEA9CIB8DEAEHHA5AEA7EDAFIFA9AHACHEA8CCA7DBA9FEF. Accessed 17 Dec 2020.

34. Zhao H, Du Y, Chen S, Qing L, Wang X, Huang J, et al. The prion protein gene polymorphisms associated with bovine spongiform encephalopathy susceptibility differ significantly between cattle and buffalo. Infect., Genet. Evol. 2015; doi:0.1016/j.meegid.2015.08.031.

\section{Table}


Table 1

Primer information.

\begin{tabular}{|c|c|c|c|c|c|}
\hline Specie & Primer & $\begin{array}{l}\text { Target } \\
\text { gene }\end{array}$ & Sequence $\left(5^{\prime} \rightarrow 3^{\prime}\right)$ & $\begin{array}{l}\text { Product size, } \\
\text { bp }\end{array}$ & Sources \\
\hline \multirow[t]{2}{*}{$\begin{array}{l}\text { Bovine and } \\
\text { ovine/caprine }\end{array}$} & $\begin{array}{l}\text { Universal } \\
\text { forward } \\
\text { primer }\end{array}$ & TAF4 & ATGGCTTAGGACCCAGCTCT & \multirow{2}{*}{$\begin{array}{l}125 \text { bp for } \\
\text { bovine } \\
\text { species;107 bp } \\
\text { for } \\
\text { ovine/caprine } \\
\text { species }\end{array}$} & \multirow[t]{2}{*}{$\begin{array}{l}\text { This } \\
\text { study }\end{array}$} \\
\hline & $\begin{array}{l}\text { Universal } \\
\text { reverse } \\
\text { primer }\end{array}$ & & $\begin{array}{l}\text { ACAR }^{1} \\
\text { CCAGAACCTGGATCGGA }^{-1}\end{array}$ & & \\
\hline \multirow[t]{2}{*}{$\begin{array}{l}\text { Internal } \\
\text { reference } \\
\text { gene }\end{array}$} & $\begin{array}{l}\text { Internal } \\
\text { reference } \\
\text { forward } \\
\text { primer }\end{array}$ & $\begin{array}{l}18 S \\
\text { rRNA }\end{array}$ & AGCCTGAGAAACGGCTACC & \multirow[t]{2}{*}{$181 \mathrm{bp}$} & \multirow[t]{2}{*}{$\begin{array}{l}\text { Yun et } \\
\text { al., } \\
2018\end{array}$} \\
\hline & $\begin{array}{l}\text { Internal } \\
\text { reference } \\
\text { reverse } \\
\text { primer }\end{array}$ & & TGCTGGCACCAGACTTGC & & \\
\hline
\end{tabular}

\section{Figures}

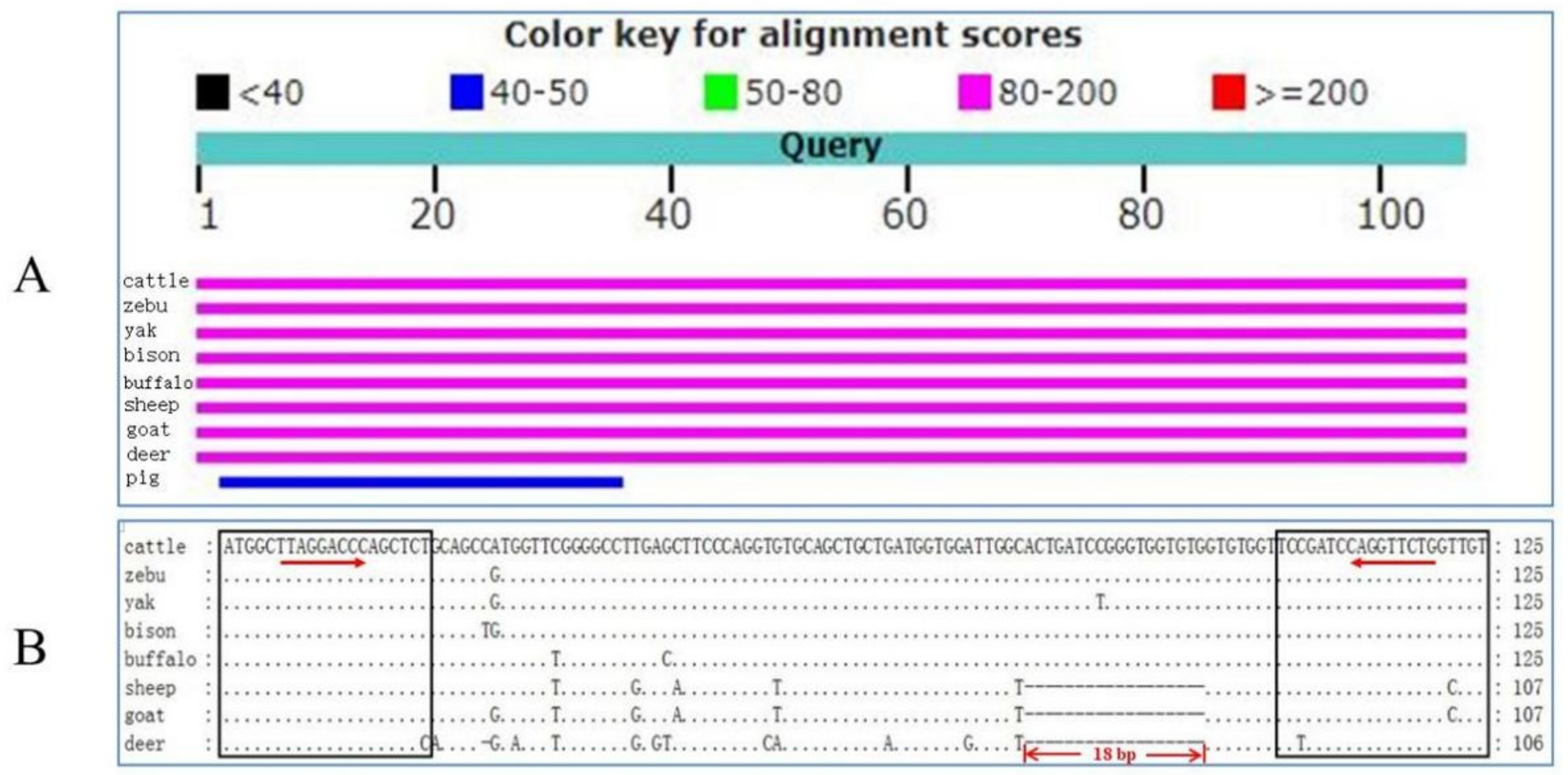

Figure 1 
BLAST alignment analysis (A) and ClustalW multiple sequence alignment results (B) for universal target DNA sequence in genome sequences of 53 species. Black box region is primer binding region; the dot (.) denotes the same base as the reference genome (cattle); the horizontal (-) denotes the deletion of the base.

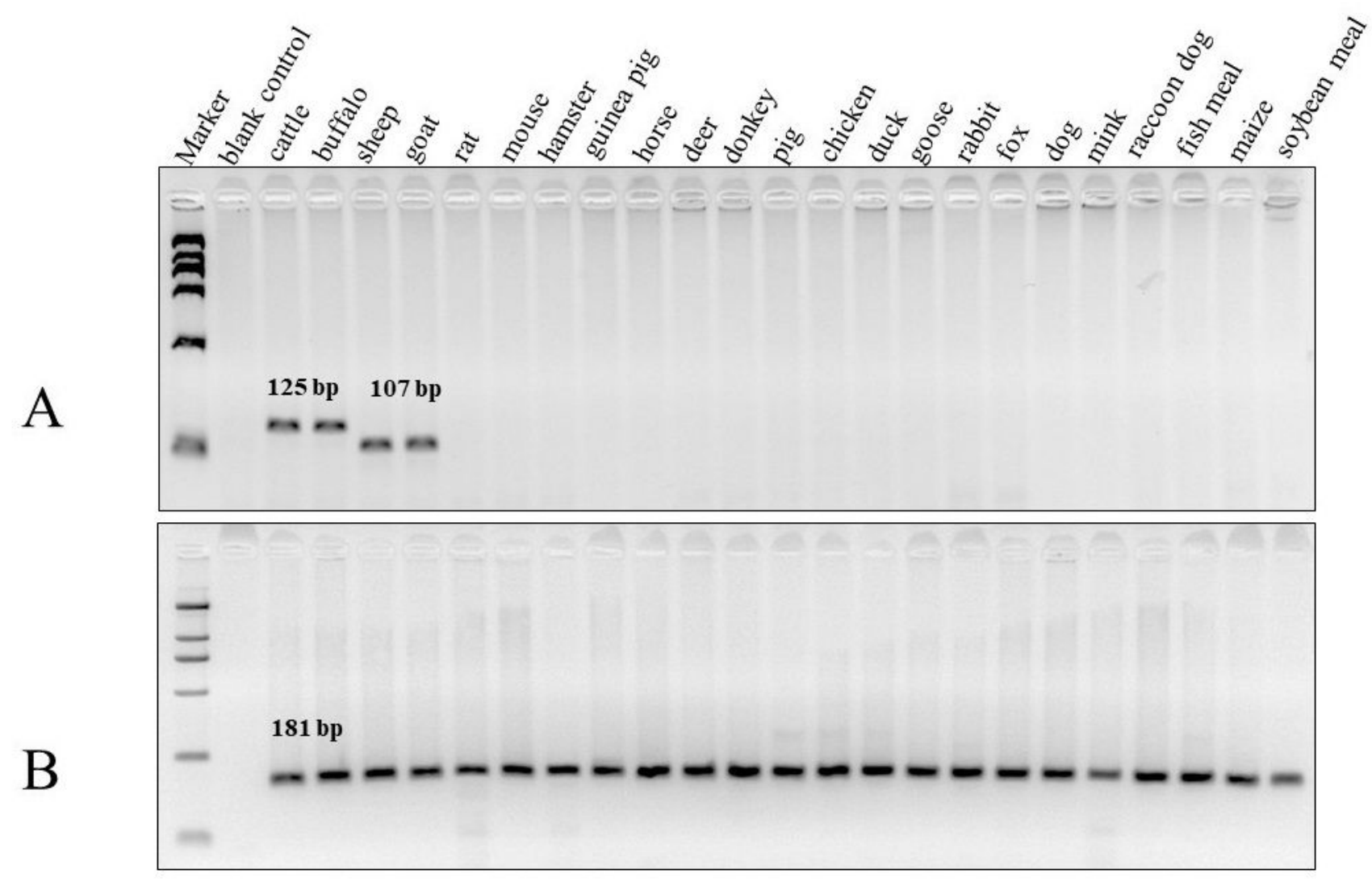

\section{Figure 2}

Specificity test of universal primer pair designed on the novel universal target DNA sequence $(A)$ and internal reference primer pair (B) with DNA from 20 animals and 3 feed materials. Marker, molecular weight marker $100-2,000$ bp gradient. Molecular sizes are indicated. The picture is reverse images of $2.5 \%$ agarose gels. 
A

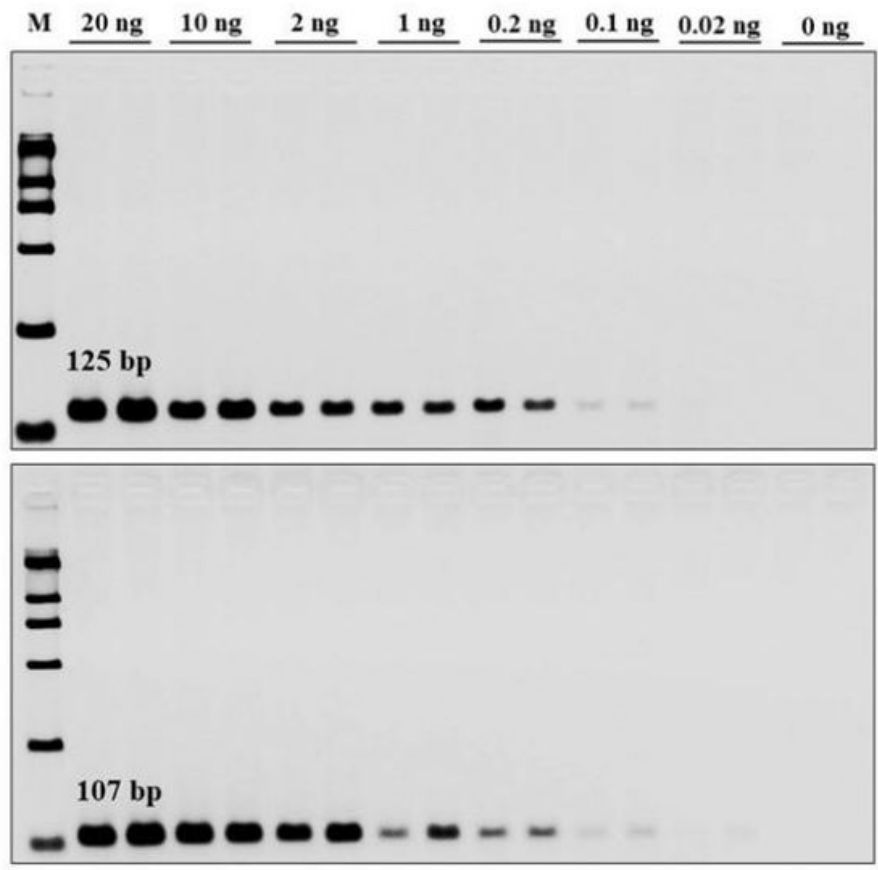

B
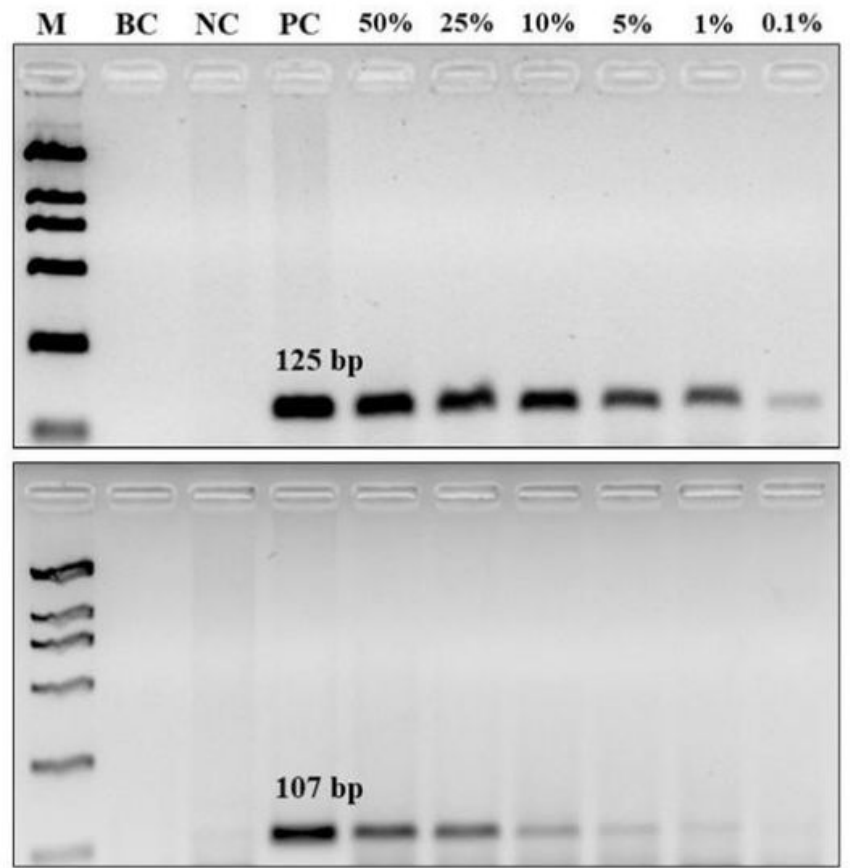

\section{Figure 3}

Sensitivity test of PCR method based on the novel universal target DNA sequence for bovine and ovine detection in different concentrations of DNA samples $(A)$ and different binary mixture samples of heattreated $\left(133^{\circ} \mathrm{C}, 300 \mathrm{kPa}\right.$ for $20 \mathrm{~min}$ ) meat and bone meal (MBM) and feeds (B). M, Molecular weight marker 100-2,000 bp gradient. Molecular sizes are indicated. The pictures are reverse images of the $2.5 \%$ agarose gels. 


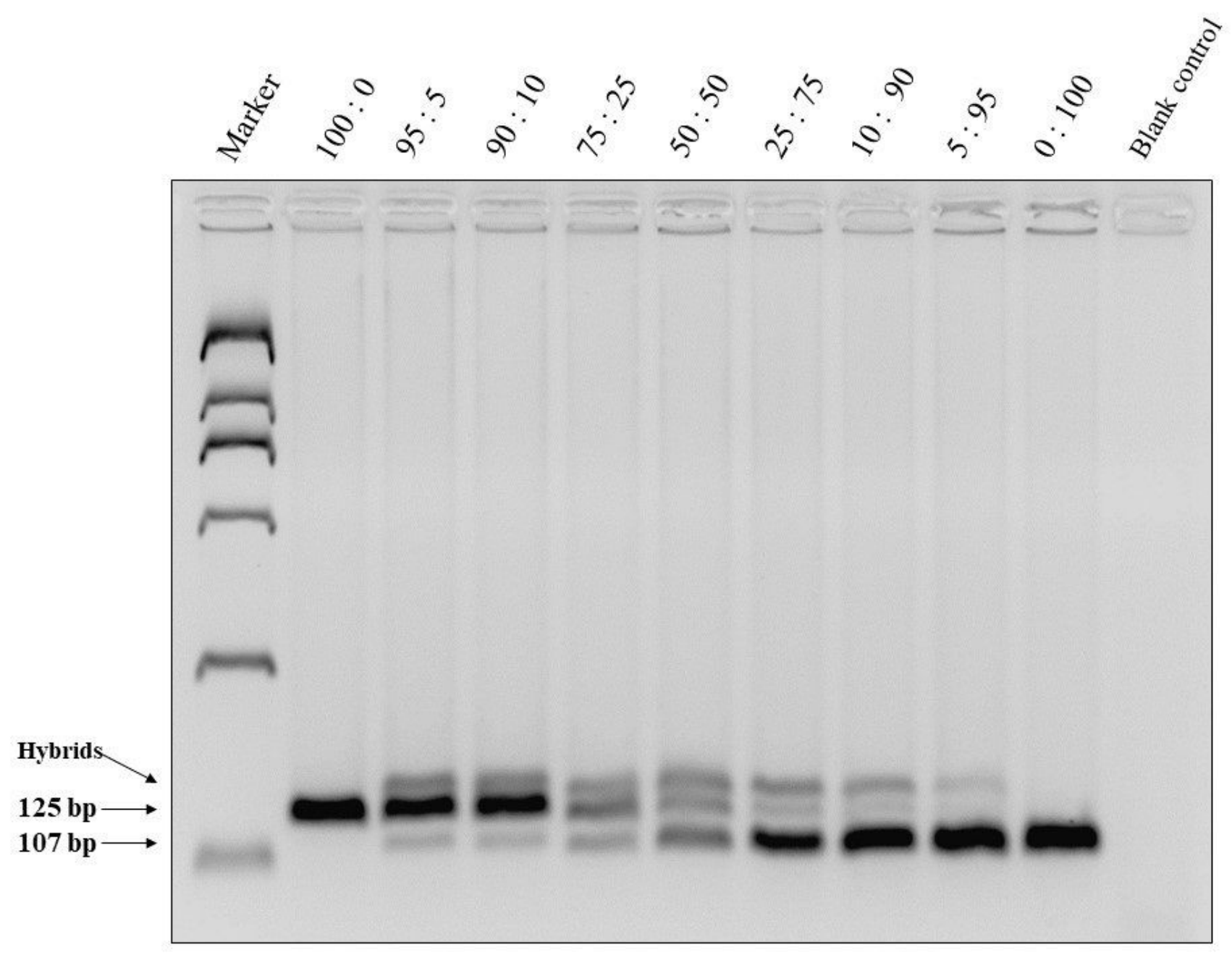

\section{Figure 4}

Co-detection of bovine and ovine $(\mathrm{w} / \mathrm{w})$ ingredients by PCR method based on the novel universal target DNA sequence. M, Molecular weight marker 100-2,000 bp gradient; BC, blank control. Molecular sizes are indicated by the arrows. The pictures are reverse images of the $2.5 \%$ agarose gels. 


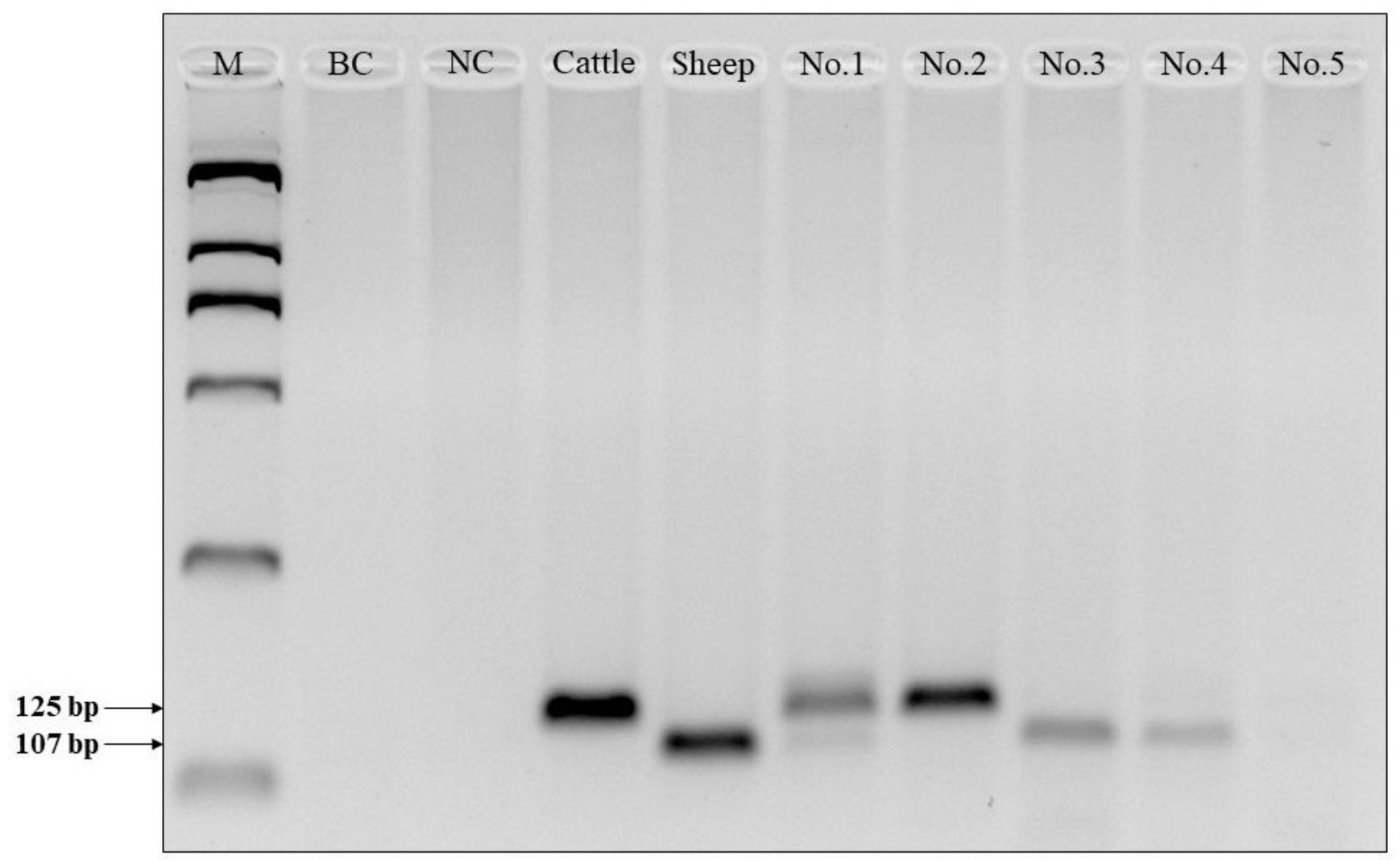

Figure 5

Application of PCR method based on the novel universal target DNA sequence for the detection of feeds samples (No. 1 to 5). M, Molecular weight marker 100-2,000 bp gradient; BC, blank control; NC, negative control. Molecular sizes are indicated by the arrows. The pictures are reverse images of the $2.5 \%$ agarose gels.

\section{Supplementary Files}

This is a list of supplementary files associated with this preprint. Click to download.

- ESupplementary.docx 